\title{
Research on the Application of PPP in the Development of Modern Ceramic Industry Heritage in Jingdezhen, Jiangxi Province
}

\author{
Ting QIU ${ }^{1, a}$ and Hui-Qiang $X U^{2, b}$ \\ ${ }^{1}$ School of Management and Economics, Jingdezhen Ceramic University (Xianghu Campus), \\ Jingdezhen, Jiangxi 333403, China; \\ ${ }^{2}$ School of Management, Central University for Nationalities, Beijing 100081, China) \\ aqiuting0731@163.com, b442179491@qq.com \\ ${ }^{*}$ Corresponding author: Ting Qiu
}

\begin{abstract}
Keywords: PPP, industrial heritage, application, Jingdezhen.
Abstract: This paper has combed the practice situation of PPP in China and clarified the feasibility of introducing PPP in the development of industrial heritage. Based on the present situation of Jingdezhen modern ceramic industry heritage and the development dilemma, it is proposed that the development of industrial heritage should be distinguished to select the PPP operation mode, the undeveloped Industrial Heritage is applied to ROT, and the developed industrial heritage can choose TBT, O\&M and MC mode; and put forward relevant countermeasures and suggestions for the obstacles faced by the implementation of PPP.
\end{abstract}

\section{Introduction}

The PPP (Public-Private Partnership, government and social capital cooperation) model has been introduced into China by the World Bank since 1995. After more than 20 years of development, it has accumulated a wealth of practical experience in China. After the Third Plenary Session of the 18th CPC Central Committee, China has strengthened the cooperation between social capital and the government. In particular, the General Office of the State Council issued the "Circular on Guidelines for Promoting Government and Social Capital Cooperation in the Public Service Sector" in May 2015 [1], which has further promoted the new round of PPP practice.

Jingdezhen, as a world-renowned porcelain city for thousands of years, has been spreading all over the millennia. The relics of the ceramic are dotted and the heritage of the modern ceramic industry is not exhaustive. The industrial heritage, which contains great cultural value, artistic value and aesthetic value, is a vivid history of ceramic industry, which tells the rise and fall of the ceramic industry. Jingdezhen is working on the rejuvenation of the "Millennium porcelain capital". and was included in the second batch of national ecological restoration City mending ("City Double Fix") list of pilot cities in March 2017, a new wave of urban reconstruction and construction is being set off. The development and utilization of the ceramic industrial heritage of the massive distribution is one of the key points of the Jingdezhen municipal government in recent years, but the traditional development mode can not meet the needs of the current development and protection. Facing the difficulties of development, it is of great significance for Jingdezhen and other cities to explore the introduction of PPP into the development of Jingdezhen modern ceramic industrial heritage.

\section{PPP and its Application in China}

\subsection{The Connotation of PPP}

"PPP" can be literally translated as "Public-Private Partnership." Its core meaning is that the public sector cooperates with the private sector to provide public goods or services. In China, PPP has been translated as "government and social capital cooperation." The official document states that "the PPP model refers to a long-term cooperative partnership between the government and the private sector in the field of infrastructure and public services"[2]. Under the PPP model, the social capital is eligible to participate in the project design, project construction and post operation, and 
mainly through the daily "user pay" and the specific conditions of "government pay" to achieve the return on investment.

Different from the traditional financing model, PPP is based on the project, and its financing is based on the project's expected revenue status and government support. In addition, under the PPP model, the project's direct operating income and the government's support subsidy income are the main source of funds for repayment of loans. The project assets held by PPP project companies and the government's limited commitment during the project's duration are the security guarantees for repaying loans. The practical experience at home and abroad shows that the use of PPP can greatly stimulate the enthusiasm of social capital to participate in the construction of public infrastructure projects, increase the investment efficiency of the public sector, and reduce the development risk of public infrastructure projects [3]. Of course, the introduction of PPP to social capital may also lead to the loss of state-owned capital and increase the risk of social capital. In practice, this model should be rationally understood and used scientifically to avoid its risks and maximize its advantages.

\subsection{The Main Operating Mode of PPP}

The history of the implementation of PPP in our country is relatively short. Compared with foreign countries, the accumulation of practical experience in projects is not deep enough. The operation mode of PPP in China can be roughly divided into three categories: outsourcing mode, franchising mode and privatization mode [4].

\subsubsection{Outsourcing Mode}

The operation mode of outsourcing class is carried out by the government as the main body of investment, in the course of the project, the responsibility of the social capital party is to contract the part of the whole project. For example, it is responsible for the construction of the project, or for the government to maintain and manage the infrastructure, and to obtain revenue from the government department at this cost. The risk of social capital in outsourcing PPP project is usually small. Outsourcing projects mainly include modular outsourcing and overall outsourcing. Modular outsourcing can be further divided into service contracting and management contracting. There are many types of overall outsourcing operations, including "design-construction", design-construction-main maintenance", "operation and maintenance", and "design-construction-operation".

\subsubsection{Franchising Mode}

The franchise mode is usually jointly invested by the social capital party and the government, and the social capital side participates in the investment of some projects or all projects. The partnership between the government and social capital partners is established through contract mechanism, so as to achieve the effect of sharing benefits and risks between the private sector and the government. The application of this mode can not only reduce the investment costs in the project cycle, but also can optimize the quality of public services. The franchising PPP can be divided into three categories: "transfer-operate-transfer" (TOT) and "build-operate-transfer" (BOT) and "other". The TOT mode can be subdivided into "purchase-update-operate-transfer", "lease-update-operate-transfer". The most widely used BOT modes are "build-lease-operate-transfer" and "build-own-operate-transfer".

\subsubsection{Privatization Mode}

The privatization mode takes the social capital as the main body of investment. The government performs its supervisory responsibilities in the implementation of the project. The investor, through the "user pay", recovers the initial investment in the project and realizes profit. In the project contract, the private sector can own the development project permanently, and the private sector therefore also bears almost all risks of the project. Under the framework of the privatization of PPP operation mode, full privatization and partial privatization are the main forms of implementation. The operation of social capital under the fully privatization mode is mainly "purchase-update-operation" or "construction-own-operate". Partial privatization mode is through 
the transfer of equity to operate.

\subsection{Application of PPP in China}

PPP originated in the United Kingdom. After decades of development, this new financing model has been praised and recognized by all countries in the world [5]. In the mid-1990s, PPP was introduced into China as a new way of project financing. In the following ten years, China has conducted many practical explorations on PPP, and the BOT has been carried out successively. The exploration and practice at this stage has laid a good foundation for the standardization and localization of PPP in the future.

2014 was a milestone year for the development of PPP in China. The Ministry of Finance has made a systematic exposition of the reasons, tasks, and methods for promoting PPP, and promoted the application of PPP models in these aspects of organization, legislation, and project pilots. In order to regulate the application of PPP, the Ministry of Finance has set up a leading group for cooperation between the Ministry of Finance and social capital. According to the statistics of the Social Capital Cooperation Center of the Ministry of Finance, as of May 1, 2017, the Ministry of Finance and the Social Capital Cooperation Center has 12287 PPP projects with a total investment of $1,454.5418$ billion yuan. The main areas were public utilities such as the government infrastructure and water conservancy construction.

With the gradual expansion of the application scope of the PPP model, it has also been adopted in the field of industrial heritage development, such as the adjustment and reconstruction of the old industrial base in the United Kingdom, Canada's Rideau Canal and other industrial heritage transformation, as well as reconstruction of the Wang Shi Ao cave site in Shaanxi and the protection and benefit of the heritage along the Wei Gong Ming channel of Tiexi District, Shenyang. So, has accumulated abundant experience.

\section{Development Status and Difficulties of Modern Ceramic Industry Heritage in Jingdezhen}

\subsection{Development Status of Jingdezhen Modern Ceramic Industrial Heritage}

Jingdezhen is famous for its porcelain production. The spread of ceramic monuments and modern ceramic industrial heritage is one of the characteristics of the city. Jingdezhen modern ceramic industrial heritage refers to the abandoned industrial buildings, kiln sites, related machinery and equipment and other industrial remains created by the ceramic industry since the founding of the People's Republic of China. (Note: if there is no special explanation, the "ceramic industrial heritage" mentioned in this article refers to the "Jingdezhen modern ceramic industrial heritage".) Among them, the "ten porcelain factory" since the founding of New China was the most typical. Since the early 1990s, Jingdezhen has begun to explore the development and reutilization of the ceramic industry heritage.

\subsection{The Status of the Developed Ceramic Industrial Heritage}

After more than 20 years of exploration, the development of Jingdezhen ceramic industrial heritage has also gained some valuable experience and achievements. In the current industrial heritage development projects in Jingdezhen, the main body of investment is the government, and the main risks and benefits of the project are borne by the government. The project construction mainly adopts the way of government reform and social capital leasing, and the income is realized through the mode of "user pay", and a small part of the social capital participates in the operation. Under the guidance of the government, the Jianguo Porcelain Factory, the Diaosu Porcelain Factory and the Yuzhou Porcelain Factory were successively built into creative industrial parks and creative neighborhoods. Jianguo Porcelain Factory and Diaosu porcelain factory were developed earlier. In the type of development pattern, it is mainly built into a ceramic creative incubation base and cultural industry demonstration site, and the cooperation mode is only the government investment transformation and private sector leasing operation; based on the Yuzhou porcelain factory, the 
development of Tao Xichuan is more in-depth than the former two. The development of Tao Xichuan has incorporated the cooperation of private capital and set up a special company to create a new type of city complex.

\subsection{The Status of Undeveloped Ceramic Industrial Heritage}

Although after more than 20 years of exploration, there are still a large number of ceramic industry heritages in Jingdezhen which have not been properly protected and developed. After investigation, it has been found that Renmin porcelain factory, Yishu porcelain factory, Hongqi porcelain factory and other industrial relics are well preserved at the current stage, but lack of maintenance. Although buildings or warehouses of some factories have been leased, they are mainly used for private logistics and warehousing, which has failed to effectively protect the heritage and value of excavation.

\subsection{The Main Difficulties Faced by the Development of the Modern Ceramic Industry Heritage in Jingdezhen}

The municipal government of Jingdezhen has realized the importance and urgency of he development and protection of heritage. In particular, under the requirements of the "city double fix" urban construction, how to develop and reutilize industrial heritage is related to the realization of urban construction goals. However, the development of the ceramic industry heritage in Jingdezhen faces the following difficulties.

\subsubsection{Insufficient Funds}

At present, the funds for the protection and development of the heritage of the ceramic industry come mainly from the government's financial appropriation, with limited funds and low use efficiency. In recent years, the total revenue and growth rate of Jingdezhen have been counted down in the province, which is lower than the provincial average. Constrained by financial resources, insufficient capital investment has made it difficult for some industrial heritage to be properly protected and developed.

\subsubsection{Patch Distribution Leads to the Complexity of Development Mode Selection}

Jingdezhen modern ceramic industrial heritage is mostly ceramic industrial plants, warehouses, kiln sites, which covers a large area, mostly scattered in the city center and suburban areas. The environmental capacity of the area is low, the residence is mixed, and the traffic is inconvenient. The distribution form objectively brings difficulties to the development and protection of the heritage, and increases the cost of development and transformation, which is also not conducive to the formation of agglomeration. The protection and development of industrial heritage is not only a matter of heritage reuse, but also a problem of coordination between a complex urban evolution and the transformation of the old city. This makes the Jingdezhen Municipal Party Committee and Government face difficulties in choosing the development mode for the modern ceramic industry heritage.

\subsubsection{The System of Value Identification and Evaluation is not Sound}

According to foreign experience, values are usually evaluated in terms of the age, uniqueness, historical value, data records, the preservation of industrial buildings and the potential of development according to the industrial heritage. The valuation of industrial heritage is a complex project because the value it contains is implicit and abstract. At present, China has not yet established a complete evaluation system for the value of industrial heritage, just clarifies the basic composition of value. There is a corresponding protection document for industrial heritage in Jingdezhen, but there is no unified standard on the value of industrial heritage. Before development, it lacks the necessary industrial heritage value evaluation mechanism, which can easily lead to profit-oriented development, often resulting in the destruction of valuable industrial heritage.

For a long time, the pattern of government-led financial commitments in Jingdezhen has not been 
adapted to the needs of heritage development and urban development. The development mode needs to be optimized.

\section{Selection and Implementation of PPP Operation Mode for the Development of the Modern Ceramic Industry Heritage in Jingdezhen}

\subsection{Status of the Application of PPP in Jingdezhen}

Since 2015, Jingdezhen has started to use pilot sites for PPP, which mainly involves cultural tourism and municipal construction. Compared with other parts of the province, the practice of PPP in Jingdezhen started relatively late, the total amount of investment and the number of projects, the Jingdezhen has occupied the bottom of the province. According to the data from the PPP Center of the Jiangxi Provincial Department of Finance, the city of Ganzhou was the first in the province with 598.30 billion yuan, while the Jingdezhen only has 4.004 billion yuan; the number of PPP entries is 97 in Ganzhou, ranking first in the province, while Jingdezhen only has 3. From the present situation of the application of PPP in Jingdezhen, as of May 2017, 6 items have been included in the Jiangxi provincial government and social capital cooperation list, including 4 municipal construction projects and 2 cultural tourism projects. The total investment of PPP projects in Jingdezhen is 6.104 billion yuan, and the social capital for supporting the introduction is 5.724 billion yuan. The current mode of operation of Jingdezhen's PPP project is all BOT mode, which is mainly the development of incremental assets, and the government owns the ownership of project assets. The source of revenue for the project is mainly ticket sales, housing rentals, and advertising and other exclusive income. This is inconsistent with the requirements of urban construction in Jingdezhen. It also shows that it is necessary to introduce a scientific and effective investment mode in the current crucial period of vigorously promoting the construction of city.

\subsection{Selection of PPP Operation Mode for the Development of the modern Ceramic Industry Heritage in Jingdezhen}

When selecting the specific operation mode of PPP, it is necessary to combine the actual development of the modern ceramic industrial heritage of Jingdezhen. The ownership of the project's assets, the income status, and how the project risks are shared are closely related to the selection of the PPP operating mode. For different development projects, PPP operation mode must be selected to adapt to the development environment. In addition, these industrial heritages are mostly owned by state-owned enterprises in the planned economy period. The ownership of the assets related to the development project should be owned by the public sector. When choosing the mode of operation, it must be possible to ensure the prevention of the loss of state-owned assets. In the current PPP project in Jingdezhen, all the operation modes are selected as BOT mode. However, this paper suggests that for the development of industrial heritage, the specific operation mode should be selected in accordance with the characteristics of different modes of PPP.

\subsubsection{For the Undeveloped Ceramic Industrial Heritage}

In view of the undeveloped ceramic industrial heritage, the development and operation mode of "Reconstruction-Operation-Transfer" (ROT) can be selected. It is an upgraded version of the "build-operate-transfer" (BOT) mode. It has added the project financing function for reconstruction and expansion in the BOT operation. ROT is mainly for development projects with long operating hours and severely damaged assets. The current protection status of Jingdezhen's modern ceramic industrial heritage is not optimistic. Many ceramic industry heritages as state-owned assets have been severely damaged. Through the "reconstruction-operation-transfer" mode, we can make full use of the advantages of social capital to achieve effective development of the ceramic industry, while preventing the loss of state-owned assets. 


\subsubsection{For the Developed Ceramic Industry Heritage}

\section{a. TBT (Transfer-Build-Transfer)}

"Transfer-Build-Transfer" is a method in which the government uses tendering to transfer stock assets that have been operating for a period of time in the previous period or project operating rights for a number of years to social capital for distribution and package it to social capital. The social capital is responsible for the later development and maintenance of the whole development project. The government obtains the equivalent of the operating right only from the projects that have been completed in the later period, and the government has the right to recover the operating right of the project after the time of the operating agreement expires.

\section{b. Operations \& Maintenance (O\&M) and Management Contract (MC)}

Both the Operations \& Maintenance and Management Contracts refer the operation and maintenance of the stock assets to the social capital. The social capital is responsible for the operation and maintenance of the project. The government only reserves the ownership of the project and pays the relevant commission fee to the social capital. Most of these modes take long-term and medium-term contracts to introduce a more effective operation team for the project and solve the problem of lack of management skills and experience in new asset projects. While the development of the modern ceramic industrial heritage is in a stage of rapid development, large-scale development has not yet formed a mature operating management group. The early development of the ceramic industry heritage was not very successful and the economic benefits of the developed projects were not optimistic. Through the introduction of the mode of O\&M, and MC, it is expected to revitalize the project operation of the developed industrial heritage, and will help to introduce professional operation management groups to solve the problems of lack of project management skills and experience.

\subsection{Obstacles to the Implementation of PPP in the Development of Jingdezhen Ceramic Industrial Heritage}

The experience of overseas PPP projects shows that there are many obstacles to the implementation of PPP projects. These obstacles are also predictable at the current stage of Jingdezhen.

\subsubsection{Risk Sharing Mechanism and Income Distribution Mechanism are not Sound}

The incompleteness of the risk sharing mechanism and the income distribution mechanism is the biggest obstacle to the current implementation of PPP in China. Judging from existing practices, the early stage of PPP project yields are generally low and the payback period is longer. PPP projects have a large investment and long payback period. They are greatly affected by policies. In particular, there is a large variability in the sustainability of payments and payment of fees paid by governments and users. Under this situation, there is a mismatch between income and risk between social capital and government capital, which weakens the enthusiasm of participants and hinders the implementation of PPP projects.

\subsubsection{Top-level design of PPP Application is not Sound}

The top-level design used in PPP practice is not sound, which has always been a major obstacle to the implementation of PPP projects. Since the mid-1990s, China has been exploring the practice of the PPP model. However, due to lack of laws and regulations and inadequate system construction, PPP projects in many fields have stalled. In the current laws and regulations of China, the top-level design that is compatible with PPP is only government regulations and rules of the ministries and commissions, but it does not fundamentally solve the problem of the inconsistent documents of the ministries and commissions [6]. At the same time, there is also a lack of necessary legal texts, so there is a lack of legal protection and regulation.

\subsubsection{The Concept of Government Lags Behind, and the Regulatory System and System are Lacking}

Although PPP has accumulated a lot of experience in the short time from trial to full 
implementation in China, there are still many problems that need further improvement. The advantages and risks of PPP coexist, and how to avoid and manage its risk factors, the government should assume corresponding responsibilities. However, PPP is still at an exploratory stage, and the regulatory system has not yet been perfected. At the same time, due to the nature of PPP government and social cooperation, many local governments including Jingdezhen still cling to the "boss" thinking, which is not conducive to the operation of PPP and the establishment of a regulatory system.

\subsubsection{Countermeasures and Suggestions on the Application of PPP in the Development of Jingdezhen Ceramic Industrial Heritage}

\section{a. To establish a Reasonable Risk Sharing and Benefit Allocation Mechanism}

The key to the effective operation of PPP lies in constructing scientific risks and benefit sharing mechanisms. When the project participants are involved in the allocation of risks, all types of risks should be borne by the most capable subjects so that they can control the risks most effectively. In terms of stimulating the enthusiasm of participating entities, the risks shared by the various entities should be matched with their respective returns. The greater the risk, the higher the rate of return should be. Of course, the risks borne by social capital should have upper limits. A reasonable and effective risk sharing mechanism and interest distribution mechanism should be established.

\section{b. To Perfect Laws and Regulations}

The clear definition of the responsibilities and risks of all parties lies in the complete legal protection, so as to protect the legitimate interests of all parties. In order to circumvent and manage the risk factors of China's PPP project, we should improve the legal system basis and strengthen the government's supervision of the whole process of PPP projects [7]. In the PPP project, the cooperation between the government and social capital can be reflected in almost the entire project cycle. Whether it is the planning and design of the initial stage of the project or the later stage of construction and operation, social capital can participate in the project. Having a well-developed supporting regulatory system that regulates the participation of all parties involved in the project is a powerful guarantee for fully stimulating the complementary advantages of the participating parties.

\section{c. Strong Support and Scientific Supervision of Government Departments}

In the PPP model, the government and social capital parties have different roles in different projects, and their responsibilities are different. However, in general, the main roles and responsibilities of the government are to provide the public with the highest quality public facilities and services. Although PPP is a more effective model for providing public facilities or services, it does not represent government governance and decision making. In any case, the government should assume the responsibility for the overall planning of the project from the standpoint of safeguarding and promoting public welfare; it should also organize the project bids in a fair manner, coordinate the task relationships among participating agencies, and strive to reduce the number of projects. Overall risk; Improve the legal and regulatory system for PPP supervision of public utilities and establish a reasonable regulatory agency system.

\section{Acknowledgement}

Jiangxi Provincial Art Science Planning Project "Mistaken Areas of Commercialization in the Protection of Intangible Cultural Heritage and Its Countermeasures: A Study Based on the Visual Threshold of Cultural Ecology” (YG2016024).

\section{References:}

[1] State Council, Notice on Promoting Guidance for Government and Social Capital Cooperation in the Public Service Sector, May 2015.

[2] China Ministry of Finance, Notice on Promoting the Use of Government and Social Capital 
Cooperation Model Issues, Financial [2014] 76.

[3] Jia Kang, Six Positive Effects of PPP Institutional Innovation, Economics. 7 (2015) 9.

[4] Wu Qiong, An Initial Probe into the Application of PPP Project Financing Model in China, Master thesis of Dongbei University of Finance and Economics. (2005) 23.

[5] Ministry of Finance, Government and Social Center, Selected Cases of Foreign PPP Cases, Beijing China Business Press, (2004) 47.

[6]Zhou Zhengxiang, Zhang Xiufang, Zhang Ping, Problems and Countermeasures in the Application of PPP Model in the New Normal State, China Soft Science. 9 (2015) 82-95.

[7] Zhao Wei, China PPP Project Failure Case Analysis and Risk Prevention, Local Finance Research. 6 (2015) 52-56. 